\title{
Discourse effects on the choice of modal adverbs in English
}

\author{
Daisuke Suzuki ${ }^{1}$, Takashi Fujiwara ${ }^{2}$ \\ ${ }^{1}$ Graduate School of Letters, Kyoto University, Japan \\ ${ }^{2}$ Faculty of Literature, Arts and Cultural Studies, Kinki University, Japan \\ https://doi.org/10.36505/ExLing-2012/05/0029/000235
}

\begin{abstract}
This study examines modal adverbs from a functional perspective, focusing on the four synonymic expressions: doubtless, no doubt, undoubtedly and without doubt. By adopting a questionnaire study, the paper aims to determine two factors regarding their patterns of occurrence: (i) whether they occur in the initial position or elsewhere in a clause; and (ii) whether the subject of the clause in which they appear is a pronoun or a full NP. The results of our analysis reveal that, compared to the other adverbials expressions above, no doubt behaves at the discourse-pragmatic level and the factors influencing their usage are strongly associated with the parameters of two different kinds of discourse.
\end{abstract}

Key words: modal adverb, synonym, function, discourse, questionnaire study

\section{Introduction}

This paper investigates whether the choice of modal adverbs in English is sensitive to the discourse context in which they occur. As illustrated by Examples $(1 \mathrm{a}-\mathrm{c})$, the four modal adverbials doubtless, no doubt, undoubtedly and without doubt are similar in form and nearly equivalent in meaning, and can thus be classified in the same semantic category:

(1) a. You have doubtless or no doubt heard the news. (Fowler 1998: 230)

b. It was no doubt clever of him to offer his resignation at that point in the proceedings. (Quirk et al. 1985: 622)

c. During the action the person will undoubtedly have certain feelings towards it and gain satisfaction from achievement. (ACAD) (Biber et al. 1999: 854)

Although the existing literature offers various interpretations of the usage of these modal adverbs (Simon-Vandenbergen and Aijmer 2007; Swan 2005; Huddleston and Pullum 2002; Biber et al. 1999; Hoye 1997; Quirk et al. 1985), it is still unclear whether discourse factors influence their use. In this paper, we will show the prominence of such discourse effects by means of a questionnaire study. ${ }^{1}$

ExLing 2012: Proceedings of 5th Tutorial and Research Workshop on Experimental Linguistics, 27-29 August 2012, Athens, Greece 


\section{Methodology}

In this study, we generated four experimental conditions by manipulating two factors regarding discourse $(2 \times 2$ design $)$. The first factor was position, referring to whether the modal adverbs occur in the initial position of the clause or elsewhere in the clause. A modal adverb positioned initially expresses the topic or theme of modality (Halliday and Matthiessen 2004, Hoye 1997, Halliday 1970). The second factor was definiteness, referring to whether the subject of the clause in which the adverbs appear is a pronoun or a full NP. This is pertinent because pronouns serve as markers of links between clauses in discourse (Halliday and Hasan 1976).

We conducted a cloze test with 16 discourse fragments, containing a choice of embedding modal adverbs (1: doubtless, 2: no doubt, 3: undoubtedly and 4: without doubt), as shown in Examples (2a-d):

(2) a. Non-Initial/Full NP

Well, tell on to the end. The archers cut them down -- a few broke back for home unscathed. Some ( ) made their way back later with their hurts.

b. Non-Initial/Pronoun

R. Jenkins has been a tower of strength in Rugby and under normal circumstances would probably have gained an International cap. He is ( ) worthy of the honour.

c. Initial/Full NP

I sampled three of them -- first in Finland, then in France and finally in Switzerland. Scandinavia is where skiing began. (_) even the Vikings got about their own snowy land on useful planks of wood.

d. Initial/Pronoun

Nora was not in the car. I keep telling you. I keep telling you. Nora went back to Germany. ( ) she is in Germany now

In this paper-based experiment, the questionnaire with 64 items (16 target fragments and 48 fillers) was administered to 40 participants, 20 of whom were native speakers of American English and 20 of whom were native speakers of British English (20 females, 20 males), all aged between 20-50 years. A total of 640 discourse completion responses (16 fragments $\times 40$ participants) were obtained and we conducted further quantitative analysis on these responses in terms of frequency.

\section{Results and Discussion}

The frequency of analysable occurrences produced in this experiment is shown in Table 1. The table shows that no doubt and undoubtedly displayed 
Discourse effects on the choice of modal adverbs in English 119

a tendency towards high frequency, but the differences were not statistically reliable enough for the two high frequency adverbials.

Table 1. Frequency and percentage of the four modal adverbials in this experiment

\begin{tabular}{|c|c|c|}
\hline \hline Modal adverbials & Freq. & $\%$ \\
\hline doubtless & 75 & 11.7 \\
\hline no doubt & 196 & 30.6 \\
\hline undoubtedly & 236 & 36.9 \\
\hline without doubt & 133 & 20.8 \\
\hline Total & 640 & 100.0 \\
\hline \hline
\end{tabular}

Table 2 shows the frequency of analysable completions when presented with the pronoun or full NP subject and the adverbial construction in the initial position or elsewhere in the clause.

Table 2. Frequencies of the four modal adverbials according to experimental conditions

\begin{tabular}{|c|c|c|c|c|}
\hline \hline & doubtless & no doubt & undoubtedly & without doubt \\
\hline Non-Initial/Full NP & 20 & 29 & 84 & 27 \\
\hline Non-Initial/Pronoun & 22 & 47 & 72 & 19 \\
\hline Initial/Full NP & 11 & 59 & 45 & 45 \\
\hline Initial/Pronoun & 22 & 61 & 35 & 42 \\
\hline \hline
\end{tabular}

One conclusion that is immediately evident is that the frequencies of the four modal adverbials varied according to the experimental conditions and uneven frequencies of scored responses illustrated that the adverbs fulfilled different functions at the discourse-pragmatic level. The participants provided the most undoubtedly completions under the Full NP conditions, whereas no doubt completions occurred the most frequently under the Pronoun conditions. The second result that is evident in Table 2 is that for no doubt and undoubtedly, significant frequency was observed between all conditions, except for between the Initial position/Full NP condition and the Initial position/Pronoun condition $(p<0.05)$. What is important is that the participants' preference for no doubt was especially strong when the Initial position involved a Pronoun. Thus, no doubt is not only merely fixed within a clause but also assumes discourse functions; no doubt can thus be used flexibly within a clause. Furthermore, two important implications follow from the results observed in this experiment. First, each of position and 
definiteness has an evident effect on the choice of modal adverbs. Second, under the Initial position conditions, the effect of definiteness was not significant, whereas under the Non-Initial position conditions, it was significant.

\section{Conclusion}

In this paper, we demonstrated that the effects of position appear to be larger than those of definiteness and that these two discourse factors variously influence the usage of modal adverbs.

\section{Notes}

1. In the field of English Linguistics, Quirk (1968) discusses the negative preterite forms of dare through adopting a questionnaire study.

\section{Acknowledgements}

This research was supported by the Japan Society for the Promotion of Science Grants-in-Aid for Scientific Research (No. 22·3983). We would like to express our sincere gratitude to Yoko Iyeiri, Masa-aki Tatsuki, Kensei Sugayama and Masa-aki Yamanashi for helpful comments on our research.

\section{References}

Biber, D., Johansson, S., Leech, G. and Conrad, S. 1999. Longman Grammar of Spoken and Written English. Harlow, Pearson.

Fowler, H. W. 1998. Fowler's Modern English Usage, 3rd ed. Revised by Burchfield, R. W. Oxford, Oxford University Press.

Halliday, M. A. K. 1970. Functional diversity in language as seen from a consideration of modality and mood in English. Foundations of Language 6, 322361.

Halliday, M. A. K. and Hasan, R. 1976. Cohesion in English. London, Longman.

Halliday, M. A. K. and Matthiessen, C. M. I. M. 2004. An Introduction to Functional Grammar, 3rd ed. London, Arnold.

Hoye, L. 1997. Adverbs and Modality in English. London, Longman.

Huddleston, R. and Pullum, G. K. 2002. The Cambridge Grammar of the English Language. Cambridge, Cambridge University Press.

Quirk, R. 1968. Co-existing negative preterite forms of dare. In Quirk, R. 1968, Essays on the English Language: Medieval ad Modern, 114-119. London, Longman.

Quirk, R., Greenbaum, S., Leech, G. and Svartvik, J. 1985. A Comprehensive Grammar of the English Language. London, Longman.

Simon-Vandenbergen, A. and Aijmer, K. 2007. The Semantic Field of Modal Certainty: A Corpus-Based Study of English Adverbs. Berlin, Mouton de Gruyter. Swan, M. 2005. Practical English Usage, 3rd ed. Oxford, Oxford University Press. 